\title{
Ethical dilemmas in prehospital emergency care - from the perspective of specialist ambulance nurse students
}

\author{
Anna Abelsson $^{1}$ (D) $\cdot$ Lillemor Lindwall $^{2}$
}

Published online: 16 May 2018

(C) The Author(s) 2018

\begin{abstract}
The aim of this study was to describe specialist ambulance nurse students' experiences of ethical conflicts and dilemmas in prehospital emergency care. In the autumn of 2015, after participating in a mandatory lecture on ethics, 24 specialist ambulance nurse (SAN) students reported experiences and interpretations concerning conflicts and ethical dilemmas from prehospital emergency care. The text consisted of 24 written critical incidents which were interpreted using hermeneutic text interpretation. The text revealed three themes: Not safeguarding a patient's body and identity; Not agreeing on the care actions; and Not treating the patient with dignity. The SANs experiences ethical dilemmas and conflict of values when they witness how others violate a patient's dignity. Discussion and reflection is based on ethical conflicts and dilemmas experienced when students see how caregivers do not safeguard the patient's body or identity. When caregivers have a conflicting will, it results in patients not being treated in an ethical manner. Also, seeing how caregivers put themselves in a power position over patients is described as an ethical dilemma that students experience when they choose not to intervene.
\end{abstract}

Keywords Human dignity - Ethical conflict - Ethical dilemma - Specialist ambulance nurse $\cdot$ Critical incident technique $\cdot$ Hermeneutic text interpretation

\section{Introduction}

This study focuses on ethics, conflicts and ethical dilemmas in clinical prehospital practice, where ethical acts belong. Ethics exists in the conflict between what the nurse

Anna Abelsson

anna.abelsson@ju.se

1 Department of Nursing Science, School of Health Sciences, Jönköping University, PO Box 1026, 55111 Jönköping, Sweden

2 Department of Health Sciences, Karlstad University, 65188 Karlstad, Sweden 
should do, must do and can do in various care situations. Ethics is combined with ethical guidelines for working life and means that when the nurse is faced with an ethically sensitive care situation, acts can have crucial consequences for the patient (International Council of Nurses 2012). Prehospital emergency care is a reality that is different to hospital-based care. When a patient asks for help from the emergency medical service, the need for care is often acute. According to Abelsson and Lindwall (2017) decision-making in this practice is often both critical, and of a complex nature. These situations can include a series of ethical conflicts that need to be taken into consideration (Jimènez-Herrera and Axelsson 2015). An ethical conflict is in the present study defined as a serious conflict of values, where the nurse must choose between different concrete alternative acts that will have consequences for other people.

Undergraduate students who study ethics in nursing have an opportunity during their clinical practice, to discuss and reflect on a range of ethical and moral actions. A progression of learning in terms of acting morally and ethically is necessary when nurses undergo training on both an undergraduate and a specialist level. Students at all levels need to continually reflect on and expand their ethical knowledge as it relates to caring for the patients. The present study is based on SAN students' stories about critical situations that they have experienced along with a SAN tutor. Care can be given in various environments, such as at an accident site or in a home. These students encounter patients in a context where care is unplanned and the patient, often involuntary, has become a patient very suddenly.

Giving care in an emergency creates a challenge and often entails a struggle to provide safe care. In the struggle to provide safe care, the nurse is sometimes faced with ethical dilemmas, as some acts are performed out of duty and not out of love for others (Abelsson and Lindwall 2017). According to Aristotle (2009), man should not focus on what is the right or wrong actions, but on which good act she, as a virtuous person, will perform. Dignified care does not merely entail medical treatment, but also shaping of an encounter and a conversation with the patient (Lindwall and Bergbom 2009). An ethical act means doing good, according to Aristotle (2009). The nurse is there and sees what happens, which means that the professional nurse has understood the situation and is then responsible for the patient (Eriksson 2007). The nurse should make a habit of taking an ethical stance. The clinical practice along with experienced specialist nurses as tutors guide the students in how to act towards patients, but also towards colleagues. An atmosphere characterized by an ethical approach helps the students develop their good and virtuous character traits (Abelsson and Lindwall 2017).

In the relationship between people, dignity emerges when the ethical and moral acts of a caregiver are reflected (Gallagher 2011; Lindwall and von Post 2014). Dignity is absolute and relative (Edlund et al. 2013). Absolute dignity is endless and impossible to renounce and includes holiness, human value, freedom, responsibility, and duty (Edlund et al. 2013). Relative dignity, on the other hand, is changeable and violable, influenced by external factors (Abelsson and Lindwall 2017).

Previous research shows that dignity is described in relation to health, illness and patient care (Baillie and Gallagher 2010; Lindwall et al. 2012). Dignity in care is achieved when patients are awarded human value (Lindwall and von Post 2008). The care acts that the nurse chooses are crucial for whether the patient experiences dignity in care (Hanks 2008). Nurses themselves note how their care acts can preserve or violate patient dignity (Lindwall et al. 2012). An ethical dilemma can present itself 
when the personal values of the nurse differ from someone else's values. In an ethical dilemma, the nurse needs to choose between two or more options, each with less than optimal moral outcomes (Rathert et al. 2016). These can be situations when other staff mistreat the patient, when the patient is prescribed care acts that he or she does not agree with or when life-support technology is used against the will of patients or family members (Browning 2013; Whitehead et al. 2015). Ethical dilemmas in prehospital emergency care can be when there is a discrepancy between rights and responsibilities (Abelsson and Lindwall 2017). The responsibility for the care of others invokes a basic human responsibility for others, and ethical dilemmas emerge in the conflict between what I am able to, must and should do (Levinas 1979; Lögstrup 1994). An ethical dilemma emerges for the students when they witness other staff's wrongful acts towards patients (Lindwall and von Post 2014). How other caregivers handle ethical dilemmas will affect how the student acts in a care situation. Having the courage to defend a patient's dignity and human value shows inner ethical strength in safeguarding the patient. The caregiver wants to protect the patient's dignity to alleviate suffering and promote wellbeing (Lindwall and von Post 2014). The most profound ethics appear in the nursing students will to defend and show respect for the patient's dignity and holiness (Eriksson 2002). Every human being chooses his or her own actions, but the most important thing is to take responsibility for those choices (Kierkegaard 1992). Because no matter how complex the situation becomes, the nurse can always choose to act on behalf of the patient.

Handling difficult ethical dilemmas can, according to Aristotle (2009), be the same as handling and working on yourself. The nurse must be aware of risks and difficulties when it comes to safeguarding the dignity of emergency care patients (Lindwall and von Post 2014). When a patient is suffering and feeling indignity, the nurse must have the courage to be a fellow man. The patients need someone with the courage to do the best for them in the sudden and unexpected situation. Through their presence, the nurses convey hope and help the patients to find meaning in what has happened (Abelsson and Lindwall 2017). Patients in all care situations, including emergencies, need dignified care (Eriksson 2007), because patients who are not treated with dignity feel humiliated (Gallagher 2011). The complexity of the care work of SANs means that ethical dilemmas can arise in different care situations. Previous research describes specific ethical dilemmas that arise within prehospital emergency care (Eraby 2014). These might include resuscitation of terminally ill patients (Henman 2017) and support to survivors of suicide victims (Nilsson et al. 2017). The aim of this study was to describe specialist ambulance nurse students' experiences of ethical conflicts and dilemmas in prehospital emergency care.

\section{Method}

This study has a qualitative approach. A hermeneutic approach inspired by Gadamer (1989) was chosen. Gadamer (1989) focuses on the concepts of pre-understanding and fusion of horizons and emphasizes that those who express themselves and those who understand are connected by a common consciousness that makes understanding possible. 


\section{Participants}

The study involved 24 registered nurses, aged 26 to 56 years, whom all attended a oneyear master program at a university to become specialist ambulance nurses. All participants had between 2 and 26 years working experience in prehospital emergency care. The inclusions criteria were students at a master program participating in dialogues about ethics and human dignity with the researchers, and that they could write in Swedish.

The method used in the education of the students participating in this study is an international ethical competence model for how nursing students can become more proficient in ethical reflection by following these articulated steps: ethical Knowing, ethical Seeing, ethical Reflecting, ethical Doing and ethical Being (Gallagher 2006). In undergraduate nurse education, students develop a basic knowledge of normative ethics. Undergraduate nurse education teaches students to reflect on ethical and moral responsibility and how they can represent the patient's interests and respect the patient's right to self-determination. When registered nurses advance to a specialist education, a progression takes place in terms of ethical knowledge and ethical thinking as well as action. The education includes objectives where the student should demonstrate the ability to, with a holistic view of man, make measurements based on relevant scientific, social and ethical aspects. This means that the education focus on ethics and ethical value issues in relation to the specialist area on an advanced nursing level. The present study adds the perspective of how SAN students experience ethical dilemmas. In their learning during their clinical placements, the students react, reflect and document the encounter with ethical dilemmas in care. This documentation is the basis for a subsequent seminar in ethics during clinical practice.

\section{Data collection}

Data were collected using the critical incident technique (CIT) (Flanagan 1954), a selfreporting technique that focuses on critical events that have affected the participants positively or negatively. Flanagan (1954, p. 335) describes the critical incident technique as: The critical incident technique should be thought of as a flexible set of principles which must be modified and adapted to meet the specific situation at hand. The students were asked to provide written critical incidents after being given the following information: Please describe a situation from your clinical reality where you experienced an ethical dilemma. Critical incidents are descriptions of actions and ways of acting that you have experienced and that have been of importance to the emergency care which you have participated in. The critical incidents were described using the following steps: It all started like this - And developed like this - I thought and acted like this. Flanagan (1954) says that critical incidents are deemed credible since the research subjects themselves have experienced them. In this article, the data covered 24 critical incidents where students experienced an ethical dilemma.

\section{Ethical considerations}

The study followed the ethical principles in accordance with the World Medical Association (2013) about anonymity, integrity and maintained public confidence. 
Ethical approval was not needed according to Swedish law (SFS 2008:192). Informed consent was obtained from each participant.

\section{Hermeneutic text interpretation}

The critical incidents described were merged into a single text which featured the reality. A hermeneutic text interpretation according to Lindwall et al. (2010) and Gadamer (1989) was conducted to explain the meaning of the text as opposed to explaining the person who wrote the text. The readers' professional pre-understanding is the basis for their understanding, which enhances or clouds views. According to Gadamer (1989), all people have an existential pre-understanding of life. However, there is a difference between existential and professional pre-understanding, and these should not be treated as equal. The professional pre-understanding of researchers is a product of care, prejudices, values, commitments and the ethics that guide nursing (Lindwall et al. 2010). The interpretation of the text was made through the following steps:

Integrating the text with the reader. The critical examination treats the text as an original source, and its relevance to reality is the foundation of validity (Lindwall et al. 2010). The first reading was an uninterrupted reading of the text from beginning to end. The text spoke to us as to a nurse in prehospital emergency care. Our professional pre-understanding made the text understandable (Gadamer 1989).

Fusion of Horizons. Through a dialogue with the text, there is a fusion of horizons, i.e., the reality of the text becomes part of the reader (Gadamer 1989). In the fusion of horizons, it became apparent how the specialist nurse students experienced ethical dilemmas in prehospital emergency care.

Putting new questions to the text. The following question was generated from the text: How do specialist nurse students experience ethical dilemmas in prehospital emergency care? The text was carefully read to discover answers to the question, i.e., significant expressions and quotations with common and distinguishing qualities (Lindwall et al. 2010). This text was processed further in the next step.

Summarizing the main themes and subthemes. The text with the quotations was carefully read, looking for its meaning: the actual common quality of all significant expressions (Lindwall et al. 2010). The common and distinctive quality was formed into three main themes. Text from the quotes was used to describe each theme. Each theme is represented by quotations taken from the original text.

New understanding. To reconfirm all themes compared to the text in search for a new understanding of the whole from its parts and the parts from the whole, which Gadamer (1989) describes as the hermeneutic circle. This process of understanding involved an abstraction of the main themes and formed a new understanding, a coherent whole which was valid and free from inner contradictions (Gadamer 1989). The processing of the data was an ongoing and reflexive process. 


\section{Findings}

The text revealed three themes Not safeguarding a patient's body and identity; Not agreeing on the care actions; and Not treating the patient with dignity. The SAN students experienced ethical dilemmas in prehospital emergency care.

\section{Not safeguarding a patient's body and identity}

Several students experienced care situations where the caregivers did not safeguard the patient's body and identity. The caregiver allowed the patient to be exposed without actively taking steps to cover the patient's body or face. The students experienced it as an ethical dilemma when they themselves did not do anything. Since they cared for the patient at a public place, the students felt that the patients were exposed to public view:

The man had tried to commit suicide, but failed, and neighbors had come to his aid. He was exposed for everyone to see on the stairs. It was difficult to establish contact with him and he tried to hide his face. I thought it was extremely offensive to exposed to others like that.

Another student wrote:

People quickly gathered around the emergency site. Anyone would have been embarrassed to be in a situation like that. She probably felt that her dignity had been violated. Afterwards, I wished I had tried to cover her face at least. So that not everyone could have seen who she was.

In prehospital emergency care, patients are occasionally surrounded by lots of people. The students describe ethical dilemmas in their stories and explain the dilemma they experience when they do not act themselves. Students see patients being violated when other staff members do not do enough to try to cover a patient's body or hide a patient's face. This gives rise to an ethical dilemma for the students, which means that they afterward often wish that they had had the courage to act differently in the specific situation.

\section{Not agreeing with the care actions}

There were situations when students experienced an ethical dilemma due to another caregiver's will, due to medical directives or because a patient's wellbeing took priority. Students felt that different caregivers did not always agree on which care acts were the best for the patient. One student experienced how the staff at a nursing home wanted to send an end-of-life patient to the hospital, while the ambulance staff wanted to let the patient die at home:

The staff wanted to send the woman to the hospital. We understood that she wouldn't survive the transport, but the doctor stood firm on the decision to 
transport her to hospital. And sure enough, the woman died halfway to the hospital, surrounded by us, who were strangers to her. We later returned to the station with an awkward feeling in our stomachs. We agreed that the best care action for the lady would have been to stay in her warm bed.

Another student experienced a similar event that meant that a patient was transported to the hospital to die instead of at the care facility:

There was a conflict between different people about how the ill person was to be taken care of. I felt that we should have accomplished a dignified care situation for the patient. Dignified would have been to die in her home and not laying on a trolley at the emergency ward.

Performing resuscitation attempts against the wishes of a family member and against one's personal ethical stance were described as a clear ethical dilemma for the students:

During the entire time that I perform CPR, the family asks me to stop. It felt unethical to perform CPR, and the chances of the patient surviving and having a dignified life are slim.

When a patient posed a danger to him-/herself and others, acts such as restraining and holding the patient against the patient's will could mean an ethical dilemma for the students:

The patient was restrained on the trolley, which he experienced as awful. He was acting out to start with, and it only got worse. I had to hold down his hands and call his name. I felt like there was no way out of the situation.

There were situations when patient care would suffer if the staff did not go against the patient's will. But going against a patient's wishes posed an ethical dilemma for the students:

The husband was upset and worried. He had no energy left. But the woman did not want to go to the hospital and said her husband could help her. I became frustrated because I understood that her husband, who was also unwell, wouldn't be able to care for her. But the woman really didn't want to go to hospital.

Students experienced ethical dilemmas when the opinions of other caregivers opposed their own about what was best for the patient. Performing caring activities that were deemed to be in the best interest of the patient, but that went against the patient's will, also entailed an ethical dilemma that was frustrating to the patients.

\section{Not treating the patient with dignity}

Placing oneself in a power position over the patients meant not respecting the patients. It could also mean to ignore the patients in what was supposed to be a caring encounter 
or to talk past or over a patient's head. The students experienced how a conversation was used to take power over the patient. Sometimes, it resulted in the patient not being given care at all:

The staff sighs and uses a nasty tone towards the patient. They start to bicker, and there's an unpleasant atmosphere. The patient, who is a bit tipsy, becomes more aggressive and refuses to go to the hospital even though he needs to. We leave the patient and go back to the station.

One student experienced how a patient ended up in both a physical and a mental disadvantage in the care situation:

He talked in an accusing manner to the patient, while he at the same time stood in a power position over a seated patient. The man has no chance to assert himself but remains in a weaker position.

The students felt that caregivers violated patients by talking about patients who were unable to defend themselves. A patient with mental illness was met with distrust:

The doctor sat and smirked at us and wondered what we thought he should do with the patient. It did not feel right that the staff had such negative preconceptions about the patient. She was obviously mentally ill, but no one took her seriously. We felt uneasy when we left her and drove away.

The students identified what they felt was wrongful behavior towards patients. They expressed sorrow and anger about the offensive actions of other caregivers towards patients. When patients are not welcomed or acknowledged, but instead ignored or exposed, these patients feel indignity. The students wished that someone had established contact with the exposed and worried patients. The students described themselves as cowardly when they chose not to intervene in care situations that were experienced as ethical dilemmas and conflicts of values.

\section{New understanding}

According to Gadamer (1989), the results lead to new understanding of how SAN students experienced ethical dilemmas. By experiencing what is described as violations against patients and choosing not to intervene, the SAN students ended up in ethical dilemmas. These ethical dilemmas arose when students did not safeguard patients when the patients' bodies or identities were exposed. This happened when students did not speak up when patients were spoken to with disrespect or when they did not object to what, in the eyes of the students, were unnecessary care actions. When patients were not acknowledged or when conversations were held above the patients' heads, an ethical dilemma arose for the students when they chose not to defend the patients.

The new understanding makes us aware that SAN students acknowledge violations and want to act to prevent them, but then refrain from doing so. When students, against their own will, choose to refrain from safeguarding patients, they have at the same time 
approved of the violation of the patient's dignity (Eriksson 2002). Even if other caregivers can be seen as passive in their defense of the patient, the students need to muster the courage to stand up for the patient (Edlund et al. 2013). However, students are often in a weak position and do not have the courage to intervene. Students might feel that it is not appropriate to point out when other caregivers humiliate patients. But experiencing how patients are offended is an ethical dilemma for nurses who want to perform ethical care. The ethical dilemma arises when a nurse witnesses another caregiver acting in an uncaring manner and thus violates the patient's dignity (Lindwall and von Post 2014).

\section{Discussion}

The present study focuses on how ambulance nurse students describe ethical dilemmas in emergency medical service. The ambulance nurse students ethical thinking is guided by their theoretical thinking. During nurse education on the specialist level, students need to learn and work with different theories. Students also need to discuss with others to create an awareness that enables them to see what they have not seen previously in their own approach. This leads to nursing students ARE ethics, in other words, reflective individuals. Gallagher (2006) development model with its four steps: ethical Knowing, ethical Seeing, ethical Reflecting, ethical Doing and ethical Being gives students skills and ability to reflect on their ethical stance and how to promote and maintains the patient's dignity.

The foundation of care is that patients have a right to make decisions for themselves. Decisions that concern their health and body must be made by patients themselves (McMullen and Philipsen 2017). But in some situations, patients are unable to speak up for themselves. An ethical dilemma might then arise when the nursing students witness a disagreement about decisions concerning the care. When an ethical dilemma arises between the nurse and another caregiver, the nurse must solve the ethical conflict in a manner that guarantees safe care, safeguards the patient's best interest and preserves the professional integrity of the nurse (American Nurses Association 2014).

Not, for example, safeguarding a patient's body and identity means that the patient's integrity is jeopardized. When that happens, the nurse has an obligation to step in and protect the patient to prevent the patient from being abandoned by the system and by the acts of other caregivers. There is also an obligation to express concerns to the head of the organization (American Nurses Association 2014). The organization that the nurse works in affects how ethical dilemmas are experienced. In organizations with ethical support for nurses, they experience less ethical dilemmas than in organizations without ethical support (Rathert et al. 2016).

The results also showed that not treating the patient with dignity caused an ethical dilemma. This meant to put oneself in a power position over the patient. The power position could be physical or verbal. Treating a person with dignity, according to Porter-O'Grady and Malloch (2015), demands emotional intelligence, a strong feeling of integrity and morals and an optimistic view of life. It requires the ability to see the other in a relationship and showing compassion towards a person in an exposed situation (Valveeva and Khakimova 2015). The students have shown that there is a type of care that is not always experienced as good for the patients. Identifying and 
acknowledging the experience of need, both from oneself and from others, and being able to provide support for those who need it becomes crucial (Heckemann et al. 2015).

\section{Limitations}

Critical incidents as a method for data collection made it possible to collect the personal descriptions of the participants. One advantage of this was that the focus shifted from attitudes to current situations. More events would have been difficult to capture through observation. However, there are limitations that bear mention. The study is based on 24 participants, which could be seen as few. Our initial aim was to describe the patients' own stories about ethical dilemmas that they had experienced in prehospital emergency care. But since patients in prehospital emergency care are exposed and vulnerable, we deemed it more appropriate to pose the question to the nurses. We think that this study highlights a central problem area tied to dignified care, care ethics and value conflicts in prehospital emergency care.

\section{Conclusion}

The students describe ethical dilemmas when they see how caregivers do not safeguard the patients' bodies or identities. When caregivers have conflicting wills, patients end up not being treated in an ethical manner. Also, seeing how caregivers place themselves in a power position over patients is described as an ethical dilemma which the students experience when they choose not to intervene.

Funding The present research received no specific grant from any funding agency in the public, commercial or non-profit sector.

\section{Compliance with ethical standards}

Conflict of interest None.

Open Access This article is distributed under the terms of the Creative Commons Attribution 4.0 International License (http://creativecommons.org/licenses/by/4.0/), which permits unrestricted use, distribution, and reproduction in any medium, provided you give appropriate credit to the original author(s) and the source, provide a link to the Creative Commons license, and indicate if changes were made.

\section{References}

Abelsson, Anna, and Lillemor Lindwall. 2017. What is dignity in prehospital emergency care? Nursing Ethics 24 (3): $268-278$. 
American Nurses Association. 2014. Code of Ethics for Nurses with Interpretive Statements. http://www.nursingworld.org/code-of-ethics. Assessed 6 January 2018.

Aristotle. 2009. The Nicomachean ethics. New York: Oxford University Press.

Baillie, Lesley, and Ann Gallagher. 2010. Evaluation of the Royal Collage of Nursing's dignity: at heart of everything we do ' campaign: exploring challenges and enablers. Journal of Research in Nursing 15: 15-28.

Browning, Annette. 2013. Moral distress and psychological empowerment in critical care nurses caring for adults at end of life. American Journal of Critical Care 22 (2): 143-151.

Edlund, Margareta, Lillemor Lindwall, Irene von Post, and Unni Lindström. 2013. Concept determination of human dignity. Nurse Ethics 20 (8): 851-860.

Eraby, Hasan. 2014. Some Ethical Issues in Prehospital Emergency Medicine. Turkish Journal of Emergency Medicine 14 (4): 193-198.

Eriksson, Katie. 2002. Caring science in a new key. Nursing Science Quarterly 15 (1): 61-65.

Eriksson, Katie. 2007. The theory of caritative caring: a vision. Nursing Science Quarterly 20: 201-202.

Flanagan, John C. 1954. The Critical Incident Technique. Psychological Bulletin 54 (4): 327-358.

Gadamer, Hans-Georg. 1989. Truth and method. London: Sheed \& Ward.

Gallagher, Ann. 2006. Promoting ethical competence. In Essentials of teaching and learning in nursing ethics: Perspectives and methods, ed. Anne J. Davis, Verena Tschudin, and Louise de Raeve. New York: Churchill Livingstone Elsevier.

Gallagher, Ann. 2011. Editorial: what do we know about dignity in care. Nursing Ethics 18 (4): 471-473.

Hanks, Robert. 2008. The lived experienced of nursing advocacy. Nursing Ethics 15 (4): $468-477$.

Heckemann, Birgit, Schols Jos, and Halfens Ruud. 2015. A reflective framework to foster emotionally intelligent leadership in nursing. Journal of Nursing Management 23 (6): 744-753.

Henman, Mary. 2017. Suicidal patients with a do-not-resuscitate order. The Journal of Emergency Medicine 52 (1): 117-120.

International Council of Nurses. 2012. International code of ethics for nurses. Geneva: ICN.

Jimènez-Herrera, Maria, and Christer Axelsson. 2015. Some ethical conflicts in emergency care. Nursing Ethics 22 (5): 548-560.

Kierkegaard, S. 1992. Either/Or: a fragment of life. Harmondsworth: Penguin Classics.

Levinas, E. 1979. Totality and infinity, an essay on exteriority. London: Martinus Nijhoff publishers.

Lindwall, Lillemor, and Ingegerd Bergbom. 2009. The altered body after breast cancer surgery. International Journal of Qualitative Studies on Health and Well-being 4 (4): 280-287.

Lindwall, Lillemor, and Irene von Post. 2008. Habits in perioperative nursing culture. Nursing Ethics 15 (5): $670-681$.

Lindwall, Lillemor, and Irene von Post. 2014. Preserved and violated dignity in surgical practice - nurse's experiences. Nursing Ethics 21 (3): 335-346.

Lindwall, Lillemor, Irene von Post, and Katie Eriksson. 2010. Clinical research with a hermeneutical design and a element of application. International Journal of Qualitative Methods 9 (2): 172-186.

Lindwall, Lillemor, Lena Boussaid, Sonja Kulzer, and Åse Wigerblad. 2012. Patient dignity in psychiatric nursing practice. Journal of Psychiatric and Mental Health Nursing 19 (7): 569-576.

Lögstrup, K.E. 1994. The ethical requirement. (In Swedish). Göteborg: Bokförlaget Daidalos.

McMullen, Patricia, and Nayna Philipsen. 2017. Conscience Clauses and Refusal to Treat: Implications for Nurse Practitioners. The Journal for Nurse Practitioners 13 (2): 138-144.

Nilsson, Christina, Anders Bremer, Karin Blomberg, and Mia Svantesson. 2017. Responsibility and compassion in prehospital support to survivors of suicide victim - Professionals' experiences. International Emergency Nursing 35: 37-42.

Porter-O'Grady, Tim, and Kathy Malloch. 2015. Quantum leadership: Advancing innovation, transforming healthcare. 4th ed. Sudbury: Jones \& Bartlett.

Rathert, Cheryl, Douglas May, and Hye Sook Chung. 2016. Nurse moral distress: A survey identifying predictors and potential interventions. International Journal of Nursing Studies 53: 39-49.

SFS. 2008:192. Act amending the Act (2003: 460) on Ethical review of research involving humans. Stockholm: The ministry of education and cultural affairs.

Valveeva, Roosa, and Elena Khakimova. 2015. Study of educational psychologists' emotional competence development. Review of European Studies 7 (5): 91-100. 
Whitehead, Phyllis, Robert Herbertson, Ann Hamric, Elisabeth Epstein, and Joan Fisher. 2015. Moral distress among healthcare professionals: Report of an institution-wide survey. Journal of Nursing Scholarship 47 (2): 117-125.

World Medical Association. 2013. Declaration of Helsinki. Ethical principles for medical research involving human subjects. JAMA 310: 2191-2194. 